\title{
Computer calculation of the mineralogical composition of raw materials
}

\author{
L.P. Chernyak ${ }^{1}$ (ORCID 000-0001-8479-0545), A. Soroka ${ }^{2}$ \\ 1 - National Technical University of Ukraine “Igor Sikorsky Kyiv Polytechnic Institute”, av. Peremogy, 37, Bldg. 21, \\ Kyiv, 03056, Ukraine \\ Tel.: +380672985775 \\ E-mail: lpchernyak@ukr.net \\ 2 - Nulogx Inc., Toronto, Canada \\ Tel: +16479816993 \\ E-mail:a-soroka@hotmail.com
}

Article info: received 29.02.2020, revised 23.05.2020, accepted 04.06.2020

Chernyak, L.P., Soroka, A. (2020) Computer calculation of the mineralogical composition of raw materials 2(47),

DOI: $10.26909 /$ csl.2.2020.3

The possibility of making of mineral astringent material of the low temperature «Mineral» computer program to determine the quantitative content of rock-forming minerals of silicate raw materials as factor in structure formation in technological processes of production and to achieve the specified properties of materials and products are shown. The results of calculations of the mineralogical composition of carbonate and clay raw materials are presented.

Varieties of raw materials used in the chemical technology of silicates are a set of certain rock-forming minerals of known chemical composition. Determination of the quantitative content of rock-forming minerals of raw materials is possible by calculations based on the initial data of chemical and qualitative mineralogical compositions.

The creation of a mathematical apparatus for processing the results of research and computer technology has increased the efficiency and efficiency of determining the quantitative content of rock-forming minerals. However, the constant increase in the number of varieties of potential raw materials makes it appropriate to improve the method of determining the quantitative mineralogical composition using computer calculations and modern software, in the direction of which the work is performed.

Determining the quantitative mineralogical composition of raw materials using the computer program "Mineral" is appropriate to optimize the charge composition of masses and technological parameters of silicate production, including ceramics, glass and binders.

The created program "Mineral" should be used by specialists of the building materials industry, production, research and design organizations working in the field of chemical technology of silicates, teachers and students of higher educational institutions.

Key words: mineral astringent, scope, mixture raw material, composition, burning.

\section{Комп'ютерний розрахунок мінералогічного складу сировини}

\author{
Л.П. Черняк ${ }^{1}$ А. Сорока² \\ 1 - Національний технічний університет Украӥни “Київький політехнічний інститут”, Київ, Україна \\ 2 - Nulogx Inc., Торонто, Канада
}

Показана можливість використання нової комп’ютерної програми «Мінерал» для визначення кількісного вмісту породоутворюючих мінералів силікатної сировини як фактора структуроутворення в технологічних процесах виробництва та досягнення заданих показників властивостей матеріалів і виробів. Наведено результати розрахунків мінералогічного складу карбонатної та глинистої сировини.

Вступ

Технологія виробництва силікатних матеріалів пов'язана з використанням великої кількості сирови- ни природного та техногенного походження з різним хіміко-мінералогічним складом $[1,2]$.

Мінералогічний склад вихідної сировини є важливим фактором структуроутворення дисперсних 
систем і матеріалів на їх основі у технологічних процесах виробництва, досягнення заданих фізико-технічних і експлуатаційних характеристик кінцевої продукції [3 - 8]. При цьому від якісного складу породоутворюючих мінералів та їх кількісного співвідношення у сировині залежать показники реологічних, структурно-механічних і технологічних властивостей водних систем (шламу, шлікерних і пластичних мас), сушильні властивості, ступінь спікання та особливості фазових перетворень при випалі.

Інструментальні методи аналізу (мікроскопія, термічний, рентгенофазовий) головним чином використовуються для визначення якісного мінералогічного складу сировини та порівняння вмісту окремих мінералів в пробах, зокрема шляхом зіставлення інтенсивності та площі характерних ендотермічних ефектів і дифракційних піків [9 - 12]. Проте для достатньо точної класифікації сировини необхідно проводити кількісне визначення вмісту кожного 3 породоутворюючих мінералів [13].

Створення математичного апарату обробки результатів досліджень та обчислювальної техніки дозволили підвищити ефективність та оперативність визначення кількісного вмісту породоутворюючих мінералів [14, 15]. Разом 3 тим постійне збільшення числа різновидів потенційної сировини обумовлює доцільність вдосконалення методики визначення кількісного мінералогічного складу із використанням комп'ютерних розрахунків і сучасного програмного забезпечення [16 - 18], в напрямку чого виконана подана робота.

Різновиди сировини, що використовуються у хімічній технології силікатів, являють собою сукупність певних породоутворюючих мінералів відомого хімічного складу. Визначення кількісного вмісту породоутворюючих мінералів сировини можливо шляхом розрахунків на основі вихідних даних хімічного та якісного мінералогічного складів.

Мета дослідження. Суть поставленої задачі зводиться до наступного:

- відомий хімічний склад певної сировини;

- відомий якісний мінералогічний склад даної сировини;

- відомий хімічний склад породоутворюючих мінералів;

- маємо визначити кількісний вміст (\%) породоутворюючих мінералів у даній сировині.

\section{Матеріали та методи досліджень}

Першим етапом роботи є визначення хімічного складу досліджуваної сировини. При цьому, на відміну від деяких інших відомих методів розрахунків, не вимагається визначати методом хімічного аналізу кількість вільного кварцу.
Наступним етапом роботи є аналіз якісного мінералогічного складу сировини методами рентгенівського, термічного та мікроскопічного досліджень.

Розв'язання поставленої задачі здійснюється програмою «Мінерал». Програма написана на мові програмування С\#. Вона може виконуватися на будь-якому ПК під управлінням операційної системи Windows.

При цьому математична постановка та алгоритм рішення задачі виглядають наступним чином.

Вихідна інформачія.

Маємо матрицю $M H$ ( $m$ рядів на $n$ стовпців) хімічного складу мінералів. В рядах матриці наведено мінерали, у стовпцях - хімічні сполуки, що входять до складу цих мінералів.

Визначено перелік породоутворюючих мінералів досліджуваної проби ( $p$ елементів, $p<=\min (m, n)$ ).

Відомий вектор хімічного складу проби сировини $A H$ ( $n$ елементів).

Вимагається визначити вектор $X$ процентного вмісту породоутворюючих мінералів у досліджуваній пробі сировини.

Алгоритм розв'язання.

Завдання розбивається на ряд окремих завдань, в кожному 3 яких вирішується система лінійних рівнянь. Матрицею системи в кожному з таких проміжних завдань є вирізка із матриці $M H р$ стовпців ( $p$-число породоутворюючих мінералів). Очевидно, що число таких проміжних завдань дорівнює числу поєднань із $n$ по $p$.

Подальше рішення зводиться до наступного:

- фіксується послідовність $p$ чисел $k_{i}(i \in[1, p])$, що представляють номери рядків в матриці для визначених породоутворюючих мінералів;

- обирається послідовність $p$ різних чисел $l_{i}$ таких, що $l_{i} \in[1, n], i \in[1, p]$;

- формується матриця $M_{i, j}=M H_{l_{i} k_{j}}$, $(i \in[1, p]), j \epsilon$ $[1, p]$ рангу $p$ з елементів основної матриці $M H$;

- формується вектор $A_{i}=A H_{l_{i}}(i \in[1, p]) 3$ елементів основного вектора $A H$;

- розв'язується система лінійних рівнянь із матрицею $M_{i j}(i \epsilon[1, p], j \in[1, p])$ та вектором правої частини $A_{i}(i \in[1, p])$;

- результат рішення чергової проміжної системи х запам'ятовується.

Програма та вихідні дані для розрахунків знаходяться в директорії C: $\mid$ Mineral. Ім'я програми Mineral.exe. Вхідні дані розміщуються у файлі Components.csv (рис. 1). Він може бути сформований і відкоректований будь-яким текстовим редактором або із застосуванням Excel.

Введення вихідної інформації для розрахунку починається з назви проби (окно Name). Наступною дією $є$ заповнення даних щодо якісного мінералогічного та хімічного складів проби (рис. 2, 3). 


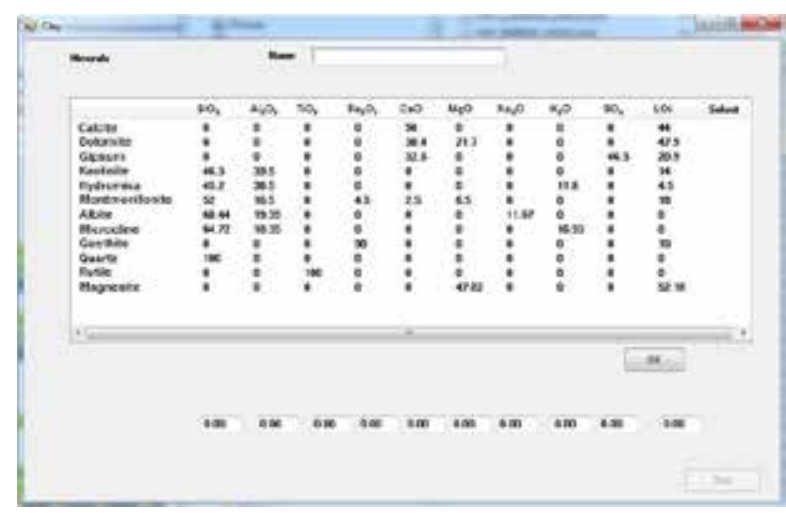

Рис 1. Вихідне вікно на екрані комп’ютера

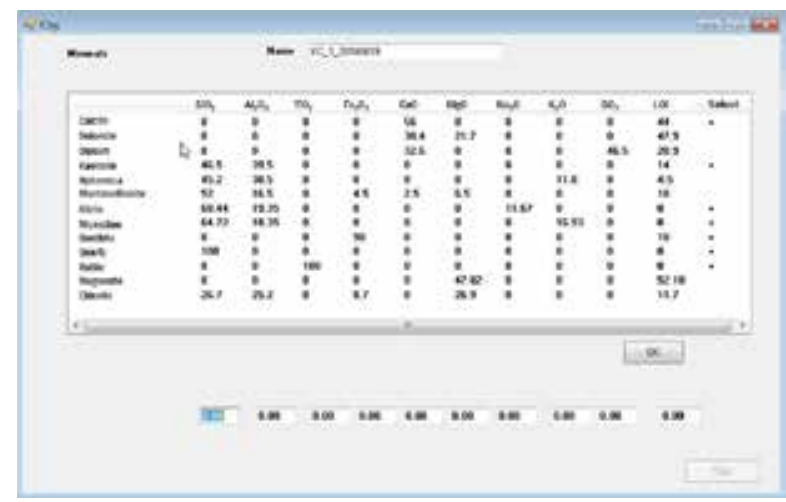

Рис 3. Програма готова до проведення розрахунку

\section{Результати та їх обговорення}

Натиск кнопки $<$ Start $>$ ініціює початок розрахунку, отримуються один або кілька коректних рішень, обчислюється їх середній вектор, результат представляється в правій колонці і на екран виводиться повідомлення про успішне завершення (рис. 4).

Приклади комп'ютерних розрахунків складу сировини.

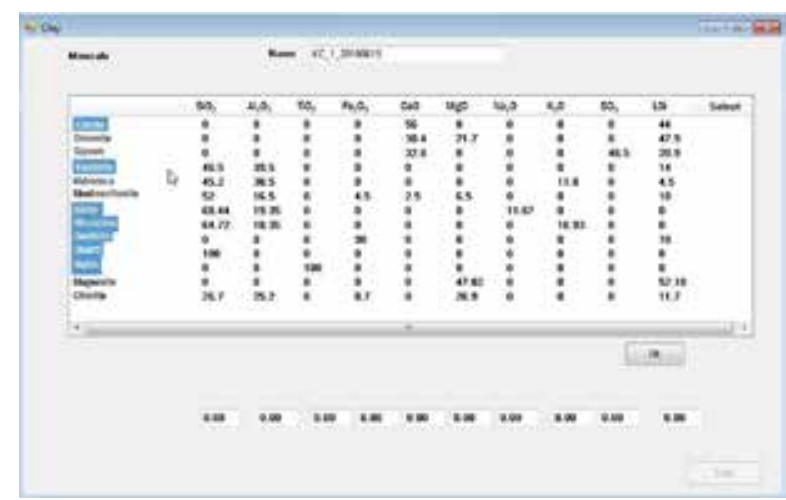

Рис 2. Якісний мінералогічний склад проби вказано

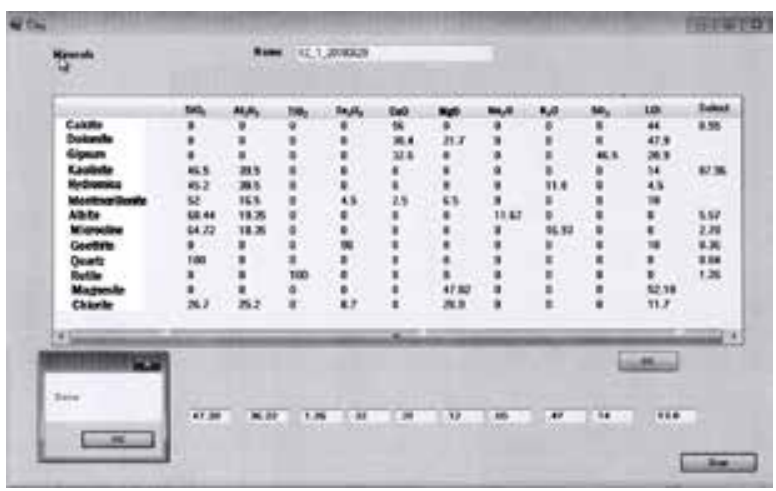

Рис 4. Завершення розрахунку кількісного мінералогічного складу

Практичним підтвердженням ефективності використання створеної програми «Мінерал» стало визначення кількісного мінералогічного складу силікатної сировини різного генезису, прикладом чого $\epsilon$ групи карбонатних і глинистих матеріалів родовищ України (табл.1, 2).

Визначено, що точність результатів комп'ютерних розрахунків залежить виключно від величини похибки вихідних даних по хімічному складу дослі-

Таблиця 1.

Мінералогічний склад карбонатної сировини

\begin{tabular}{|l|c|c|c|c|c|}
\hline \multirow{2}{*}{ Сировина } & \multicolumn{5}{|c|}{ Вміст породоутворюючих мінералів, мас. \% } \\
\cline { 2 - 6 } & кальцит & доломіт & кварц & каолініт & гідроксиди заліза \\
\hline Крейда & 97,62 & 1,15 & 0,48 & 0,63 & 0,14 \\
\hline Вапняк & 93,02 & 2,40 & 3,06 & 0,15 & 1,17 \\
\hline Черепашник & 81,30 & 13,46 & 1,84 & 3,19 & 0,54 \\
\hline Мергель & 73,33 & 3,13 & 10,01 & 14,30 & 1,90 \\
\hline
\end{tabular}


ISSN 2521-6694 (Print) Ceramics: science and life, 2(47), 2020

Таблиця 2.

Мінералогічний склад глинистої сировини

\begin{tabular}{|l|c|c|c|c|c|c|c|c|c|}
\hline \multirow{2}{*}{ Сировина } & \multicolumn{7}{|c|}{ Вміст породоутворюючих мінералів, мас. \% } \\
\cline { 2 - 10 } & каоліни & $\begin{array}{c}\text { гідро- } \\
\text { слюда }\end{array}$ & $\begin{array}{c}\text { монтмри- } \\
\text { лоніт }\end{array}$ & кварц & кальцит & \multicolumn{2}{|c|}{ польовий шпат } & гідроксиди \\
залізі & мікроклін & рутл \\
\hline $\begin{array}{l}\text { Глина } \\
\text { кривинська }\end{array}$ & 2,97 & 22,88 & 31,38 & 31,16 & 4,55 & 2,57 & - & 4,62 & 0,79 \\
\hline $\begin{array}{l}\text { Веско- } \\
\text { Гранитик }\end{array}$ & 53,29 & 17,29 & - & 22,24 & - & 3,60 & - & 1,09 & 1,39 \\
\hline $\begin{array}{l}\text { Каолін } \\
\text { КО-1 }\end{array}$ & 94,23 & - & - & 2,31 & - & - & - & 0,76 & 1,00 \\
\hline $\begin{array}{l}\text { Каолін } \\
\text { КС-1 }\end{array}$ & 85,19 & 3,98 & - & 2,03 & - & 5,57 & - & 0,36 \\
\hline $\begin{array}{l}\text { Каолін } \\
\text { КССК }\end{array}$ & 36,60 & - & - & 35,48 & 0,55 & 5,14 & 20,91 & 0,36 & 0,33 \\
\hline
\end{tabular}

джуваної сировини та діагностики породоутворюючих мінералів.

При цьому наявність таких похибок виявляється при відсутності результатів розрахунку або при їх очевидній не відповідності введеним даним хімічного чи інструментальних методів аналізу.

\section{Висновки}

Визначення кількісного мінералогічного складу сировинних матеріалів із застосуванням створеної комп'ютерної програми «Мінерал» доцільне для оптимізації шихтових складів мас і технологічних параметрів силікатних виробництв, в тому числі кераміки, скла та в'яжучих речовин.

Створена програма «Мінерал» має бути використана фахівцями промисловості будівельних матеріалів, виробничих, науково-дослідних і проектних організацій, що працюють в галузі хімічної технології силікатів, викладачами та студентами вищих навчальних закладів.

\section{References}

1. Комплексное развитие сырьевой базы промышленности строительных материалов Удачкин И.Б., Пащенко А.А., Черняк Л.П., Захарченко П.В., Семидидько А.С., Мясникова Е.А. - К.: Будівельник. 1988. - 104 c.

2. WE Worrall, Ceramic Raw Materials, 2nd Edition. Pergamon Press. - 1982. - 116 p.

3. Christopher W. Sinton. Raw Materials for Glass and Ceramics: Sources, Processes, and Quality Control, 1st Edition. Wiley. - 2006. - 368 p.
4. D. Đukić, D. Lazić, D. Drljača, M. Imamović. Characterization of raw materials and final product in the cement production. Bulletin of the Chemists and Technologists of Bosnia and Herzegovina. - 2018. - № 51. P. 47 - 52.

5. Ничипоренко, С.П., Кругличякий, Н.Н., Панасевич, А.А., Хилько, В.В. Физико-химическая механика дисперсных минералов / под общ. ред. С.П. Ничипоренко. - Киев: Наукова думка. - 1974. - 246 с.

6. Черняк, Л.П., Гонтмахер, В.Е. Минералогический состав и спекание глинистых систем. Стекло и керамика. - 1980. - № 5. - С. 22 - 23.

7. R. Géber et al., Optimization of the Mixing Ratio of Two Different Clays Used for Ceramic Roof Tiles. Materials Science Forum. - 2010. - Vol. 659. - P. 477 - 482.

8. Черняк, Л.П. Мінералогічний склад і напрямки застосування глинистої сировини Зб. Матеріали V міжнародної науково-технічної конференції «Композиційні матеріали». - Київ: НТУУ «КПІ». 2010. - C. 30 - 33.

9. Быстриков, А.С. К вопросу о количественном определении кварца на дифрактометре УРС-50И. Труды института НИИстройкерамика. - 1963. Вып. 21. - С. 133 - 139.

10. Соколов, В.Н. Количественный анализ микроструктуры горных пород по их изображениям в растровом электронном микроскопе. Соросовский образовательный журнал. - 1997. - № 8. - С. 72 - 78. 11. S. Kaufhold, M. Hein, R. Dohrmann, K. Ufer Quantification of the mineralogical composition of clays using FTIR spectroscopy. Vibrational Spectroscopy. 2012. - Vol. 59. - P. 29 - 39.

12. E. Zeelmaekers, M. Honty, A. Derkowski and others Qualitative and quantitative mineralogical composition 
of the Rupelian Boom Clay in Belgium. Clay Minerals, Journal of Fine Particle Science. - 2015. - Vol. 50. - Is. 2. - P. $249-272$.

13. ДСТУ Б В.2.7-60-97. Сировина глиниста для виробництва керамічних будівельних матеріалів. Класифікація. - К.: Держкоммістобудування України. 1997. $-12 \mathrm{c}$.

14. Черняк, Л.П., Нестеренко, И.П., Сорока, А.С. Определение минералогического состава глинистого сырья с помощью ЭВМ. Стекло и керамика. 1979. - № 3. - С. 17 - 19.

15. Розен, О.М., Аббсов, А.А. Количественный минеральный состав осадочных пород: расчет по пе- трохимическим данным, анализ достоверности результатов (компьютерная программа MINLITH). Литология и полезные ископаемые. - 2003. - № 3. C. 299 - 312.

16. Роберт У. Себеста. Основные концепции языков программирования. Concepts of Programming Languages. Пер. с англ. 5-е изд. - М.: Вильямс. 2001. -672 c.

17. Черпаков, И.В. Основы программирования. Учебник и практикум. - М.: Изд-во Юрайт. - 2016. $219 \mathrm{c}$.

18. David Thomas, Andrew Hunt. The Pragmatic Programmer. Addison-Wesley. - 2019. - 320 p. 